\title{
Purchasing Over The Counter (OTC) Medicinal Products Containing Codeine - Easy Access, Advertising, Misuse and Perceptions of Medicinal Risk
}

John S G Wells ${ }^{1}$, Michael Bergin ${ }^{1}$, Marie Claire Van Hout ${ }^{2}$, Pádraig McGuinness ${ }^{3}$, Jaco De Pleissis ${ }^{4}$, Eileen Rich ${ }^{5}$, Siphokazi Dada $^{5}$, Richard Wells ${ }^{6}$, Martina Gooney ${ }^{1}$

\begin{abstract}
${ }^{1}$ School of Health Sciences, Waterford Institute of Technology, Waterford, Ireland; ${ }^{2}$ Public Health Institute, Liverpool John Moores University, Liverpool, United Kingdom; ${ }^{3}$ CARA Pharmacy Group, Donegal, Ireland; ${ }^{4}$ The Local Choice Pharmacies, Delmas, South Africa; ${ }^{5}$ Alcohol Tobacco and Other Drug Research Unit, South African Medical Research Council, Cape Town, South Africa; ${ }^{6}$ Weldricks Pharmacy, Doncaster, United Kingdom.
\end{abstract}

Received, June 29, 2018; Revised, July 9, 2018; Accepted July 10, 2018; Published, July 10, 2018.

\begin{abstract}
Purpose. Codeine containing medicines can carry a number of health risks associated with the increase in reported misuse and dependence, however they are still readily available over the counter (OTC) in many countries. The aim of this novel study was to report on the results of a survey of customers purchasing OTC codeine containing medicinal products at pharmacies in Ireland, South Africa and England; exploring use, sources of knowledge and perception of risks. Methods. The study design was an exploratory cross sectional survey. It involved a customer self-administered questionnaire at the point of purchase $(n=1230)$. Relationships between categorical variables were analysed using Pearson chi-square for bivariate analysis. Continuous scale variables were analysed using one way analysis of variance. Results. In Ireland $6 \%$ stated they purchased codeine containing products weekly, in South Africa 13\% and in England 16\%. In Ireland and England women are more likely to view codeine containing products as harmful. In England older adults are more likely to perceive codeine containing products as harmful. A higher proportion of customers in South Africa opposed restricting codeine containing products to prescription only when compared with people in Ireland and England. Conclusions. Codeine containing products are widely purchased and used in all three jurisdictions. Whilst the majority of customers appear to have some awareness and knowledge of risks, it does not materially impact on their purchasing behaviour with a substantial minority purchasing/using such products on a weekly basis. This regularity of purchase whilst indicative of the popularity of such products, may also be a potential indicator of misuse. Future research is needed in relation to cultural and gendered differences and targeted information giving and harm reduction initiatives for safe usage of these medicinal products.
\end{abstract}

\section{INTRODUCTION}

Codeine (3-methylmorphine) is a weak opioid, widely used for its analgesic, antitussive and antidiarrheal properties. Commonly used to manage mild to moderate pain, it is available in low dose non-prescription medicinal products in a number of countries (1-2). Over the counter (OTC) purchase of codeine based analgesic products without medical consultation occurs in many countries and even in countries where it is regulated, purchase and use is considerable (3). There is little comparative international data exploring differences in customer use, sources of information and knowledge of OTC codeine containing products between countries which allow non-prescription purchase. This paper reports on a study that aimed to address this gap through a survey of customers purchasing such products at participating community/ commercial outlet pharmacies in Ireland, South Africa and England.
Deregulation has led to increased customer access, choice, self-medication and pharmacist empowerment with regards to codeine and nonopioid analgesic dispensing $(4,5,6)$. Consequently, the misuse of these products appears to be on the increase $(2,7)$; with access to open purchase lessening the consumers' ability to recognise problematic use and dependency (9-10). Public perception and possibilities for opioid tolerance within a short timeframe contributing to habitual use, misuse and dependence (8). Awareness of the dangers associated with these products is somewhat mixed. Bower and colleagues found that consumers tended not to approach the use of OTC medicines with the same level of caution and care as they displayed towards prescribed medication. (11).

Correspondence Author: Dr Martina Gooney, School of Health Science, Waterford Institute of Technology, Waterford, Ireland, Email: mgooney@wit.ie 
Research indicates OTC analgesics and other codeine based medicinal products are frequently taken inappropriately and that consumers are generally unaware of the potential of the physical harms that can result $(12-14,4)$. However, there is some evidence which suggests that public awareness of harm risks is improving (15-16).

Direct to consumer advertising (DTCA) is a significant avenue through which pharmaceutical companies promote medicinal products to consumers (17-19). DTCA creates product awareness and encourages use amongst consumers. DTCA empirical research in relation to medicinal products is not extensive and tends to focus on national rather than international contexts. The available studies indicate that DTCA can be a significant source of information and is highly influential in relation to consumer choice of product, use of such products and belief in product safety (19$21)$; particularly if the product is regularly and widely advertised (22-25). DTCA can also be a considerable source of tension between the consumer and professional pharmacists (26), as consumers appear to trust and pay attention to DTCA messages rather than the informed opinion of pharmacists encountered at the point of purchase (25-29).

\section{METHODS}

\section{Study Design}

This study adopted an exploratory, cross sectional design, involving a self-administered questionnaire to collect data from consumers at the point of purchase with a purposive sample who, at the time of survey, purchased OTC medicinal products in pharmacies in Ireland; South Africa and England. Customers who were aged 18 or over and were able to read in English were asked to participate. Thirtysix questionnaires contained too many missing values and were therefore excluded from analysis. Hence the final sample consisted of 1230 customers across all three countries. Ethical approval was received in August 2016 from research institutions in Ireland; South Africa and England.

\section{Questionnaire development}

The questionnaire, based on previously published literature, was assessed for content validity by the research team (academic researchers and experts in pharmacology, addiction and pharmacovigilance). Pilot testing was conducted in three outlets to test the survey form. Following on from this pilot, some items were changed and the overall number of items reduced.
The final 18 item questionnaire consisted of closed-, open-ended and Likert scale response items covering demographics; use of OTC codeine containing medicines; purchasing patterns of such products; views on their safety and availability. The survey was anonymous and no individuals could be identified through their responses.

\section{DATA ANALYSIS}

The statistical package SPSS v.22 was used for analyses. To examine relationships with other study variables, the demographic variables of gender; marital status; age; education and employment status were treated as categorical data. Variables relating to the use of OTC codeine containing products and knowledge pertaining to where to purchase such medicines were also treated as categorical data. Relationships between these variables were analysed using standard statistical methods for categorical data - Pearson chi-square for bivariate analysis.

The questionnaire's final section contained 5 closed-ended statements, measured on a Likert scale. The data was treated as continuous and each category was recoded to indicate positive or negative agreement with each of the statements. This produced a scale of +2 to -2 where +2 showed the strongest agreement and -2 indicated the strongest disagreement. Neutral responses were scored as 0 . Consequently, the data was analysed mainly using parametric methods. Adjoining categories within these items were collapsed; strongly agree and agree were combined; neutral was treated as a separate category and finally, disagree and strongly disagree were also merged. The percentage agreement and frequencies were then presented as an indication of the overall level of agreement with the statements. Additionally, these variables were subsequently treated as categorical and were analysed by Pearson chi-square and the results were then compared.

\section{RESULTS}

\section{Profile of respondents}

Demographics for each country are presented in Table 1.

\section{Use of Codeine containing products medicine}

The majority of respondents took codeine containing medicines to treat pain; however $2 \%$ in Ireland and $0.5 \%$ in England took these medicines to help them to relax, compared to $6 \%$ in South Africa (Fig. 1).

In both Ireland and England the proportion of males $(77 \%, 70 \%)$ who had taken codeine containing medicines was not significantly different to females $(81 \%, 80 \%)$. However, a difference was seen in 
South Africa, where $74 \%$ of males took these medicinal products compared to $79 \%$ of females and there was a significant association between gender and use of Codeine containing products medicine $\left(\chi^{2}(2, \mathrm{n}=665)=6.40, p=0.04\right.$, phi=0.10).

Nineteen percent and $15 \%$ of respondents in Ireland and England indicated they did not read the information leaflet, whereas in South Africa this figure was roughly a third at $29 \%$ (Table 2). Chisquare test for independence indicated a significant association between country and reading advice $\left(\chi^{2}(4, \mathrm{n}=1027)=25.60, p=0.00\right.$, phi=0.16). There were no statistically significant results in terms of gender and reading advice; however in all three countries the proportion of females reading the advice was always higher than for males.

A significantly higher proportion of English respondents (94\%) stated they consumed combination codeine containing analgesics $\left(\chi^{2}(4\right.$, $\mathrm{n}=1020)=94.81, p=0.00, p h i=0.31)$. Furthermore,
English respondents (80\%) seemed more aware of the warnings associated with paracetamol packaging $\left(\chi^{2}(2, \mathrm{n}=297)=16.28, p=0.00\right.$, phi=0.23).

The majority of Irish respondents (42\%) took codeine containing products less than once a month (Fig. 2). In South Africa, 17\% took such products a couple of times a week and $17 \%$ stated less than once a month. In England, 26\% of respondents stated they consumed these products less than once a month but this was followed closely by $22 \%$ who stated at least a couple of times a week.

In all three countries, respondents stated constipation, drowsiness and nausea among the unpleasant side effects. In South Africa, these also included dizziness and dependence. In England side effects included dizziness and headache. All three countries were very similar in relation to the proportion that had experienced these unpleasant side effects $(12 \%$ in Ireland, $14 \%$ in South Africa and $16 \%$ in the U.K.).

Table 1. Demographic profile of respondents

\begin{tabular}{|c|c|c|c|c|c|c|}
\hline \multirow[t]{2}{*}{$\mathrm{N}=1230$} & \multicolumn{2}{|c|}{$\begin{array}{l}\text { Ireland }^{\mathrm{a}} \\
(\mathrm{N}=\mathbf{3 2 8})\end{array}$} & \multicolumn{2}{|c|}{$\begin{array}{l}\text { South Africa }{ }^{a} \\
(N=665)\end{array}$} & \multicolumn{2}{|c|}{ England $^{\text {a }}(\mathrm{N}=237)$} \\
\hline & $\mathbf{n}$ & $\%$ & $\mathbf{n}$ & $\%$ & $\mathbf{n}$ & $\%$ \\
\hline \multicolumn{7}{|l|}{ Gender } \\
\hline Male & 80 & 25 & 266 & 42 & 95 & 41 \\
\hline Female & 243 & 75 & 374 & 58 & 139 & 59 \\
\hline \multicolumn{7}{|l|}{ Age } \\
\hline Over 18 & 26 & 8 & 44 & 7 & 8 & 3 \\
\hline $21-30$ & 86 & 27 & 141 & 21 & 57 & 24 \\
\hline $31-40$ & 77 & 24 & 164 & 25 & 40 & 17 \\
\hline $41-50$ & 66 & 20 & 141 & 21 & 44 & 19 \\
\hline $51-60$ & 44 & 14 & 92 & 14 & 40 & 17 \\
\hline $61-70$ & 21 & 6 & 47 & 7 & 27 & 12 \\
\hline 71 and over & 5 & 1 & 31 & 5 & 19 & 8 \\
\hline \multicolumn{7}{|l|}{ Marital status } \\
\hline Married/living with partner & 174 & 54 & 359 & 56 & 137 & 59 \\
\hline Never married & 107 & 33 & 163 & 25 & 45 & 19 \\
\hline Divorced / Separated & 21 & 7 & 78 & 12 & 32 & 14 \\
\hline Widowed & 19 & 6 & 43 & 7 & 18 & 8 \\
\hline \multicolumn{7}{|l|}{ Education } \\
\hline Primary School & 10 & 3 & 16 & 2 & 4 & 2 \\
\hline Secondary / High School & 105 & 32 & 360 & 55 & 109 & 47 \\
\hline College & 209 & 65 & 279 & 43 & 120 & 51 \\
\hline \multicolumn{7}{|l|}{ Employment status } \\
\hline Employed & 231 & 71 & 483 & 73 & 141 & 60 \\
\hline Unemployed & 21 & 6 & 48 & 7 & 30 & 13 \\
\hline Homemaker & 29 & 9 & 36 & 6 & 14 & 6 \\
\hline Student & 20 & 6 & 29 & 5 & 7 & 3 \\
\hline Unable to work due to a chronic condition & 7 & 2 & 8 & 1 & 4 & 2 \\
\hline Retired & 18 & 6 & 55 & 8 & 39 & 16 \\
\hline
\end{tabular}




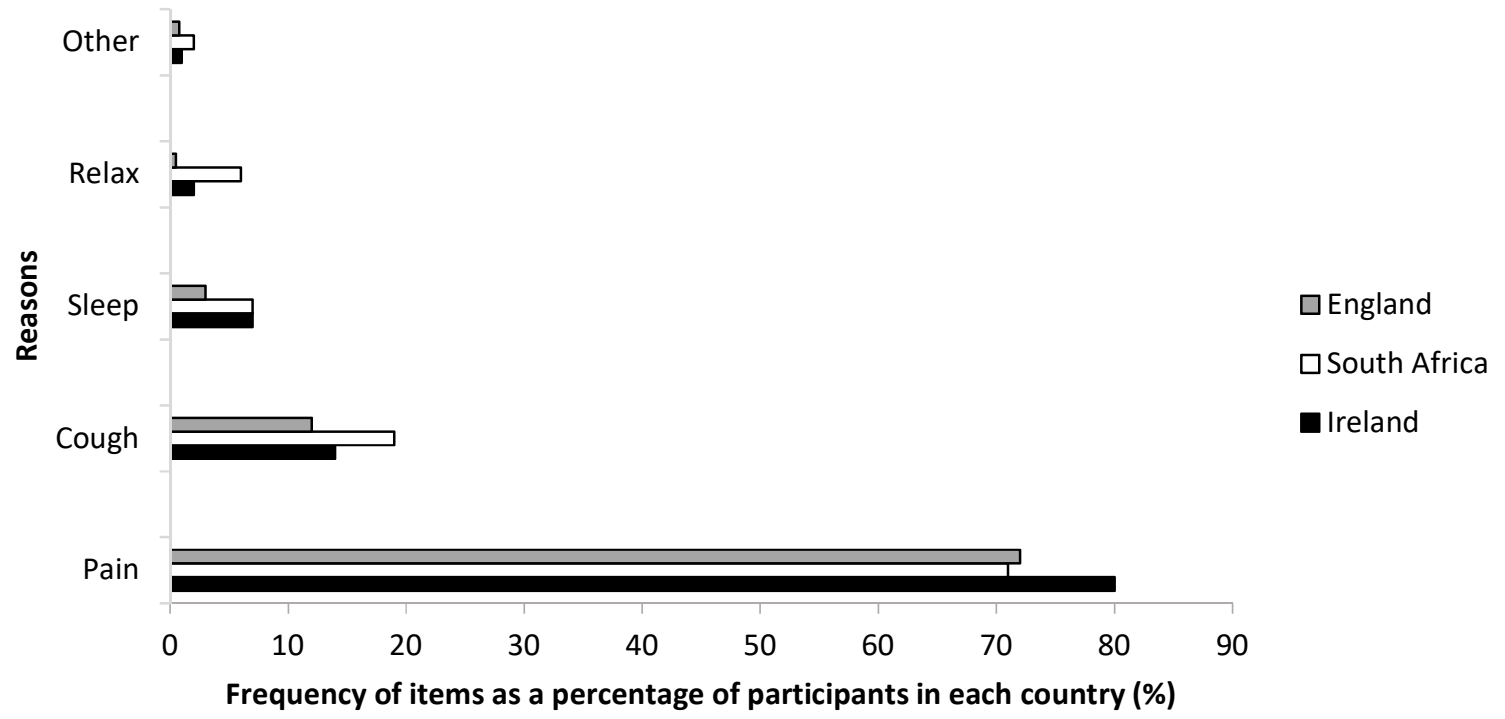

Figure 1. Reasons cited for taking codeine containing products

Table 2. Advice and warnings

\begin{tabular}{|c|c|c|c|c|c|c|}
\hline \multirow[t]{2}{*}{$\mathrm{N}=1027$} & \multicolumn{2}{|c|}{ Ireland } & \multicolumn{2}{|c|}{ South Africa } & \multicolumn{2}{|c|}{ England } \\
\hline & $\mathbf{n}$ & $\%$ & $\mathbf{n}$ & $\%$ & $\mathbf{n}$ & $\%$ \\
\hline \multicolumn{7}{|c|}{ Read advice ${ }^{* * *}$} \\
\hline Yes & 216 & 78 & 390 & 69 & 150 & 80 \\
\hline No & 54 & 19 & 161 & 29 & 27 & 15 \\
\hline Don't know & 7 & 3 & 11 & 2 & 11 & 5 \\
\hline \multicolumn{7}{|c|}{ Used combination analgesic $^{* * *}$} \\
\hline Yes & 173 & 64 & 306 & 55 & 176 & 94 \\
\hline No & 58 & 21 & 164 & 29 & 5 & 2 \\
\hline Don't know & 41 & 15 & 90 & 16 & 7 & 4 \\
\hline \multicolumn{7}{|c|}{ Notice paracetamol warning ${ }^{* * *}$} \\
\hline Yes & 99 & 65 & - & $\overline{-}$ & 116 & 80 \\
\hline No & 41 & 27 & - & - & 13 & 9 \\
\hline Don't know & 12 & 8 & - & - & 16 & 11 \\
\hline
\end{tabular}

In relation to the purchase of Codeine containing products, in Ireland, 65\% stated that they purchased these products in the local pharmacy; a higher percentage (73\%) stated the same in South Africa. However, in England the percentage was only $45 \%$ (Table 3). In Ireland and England, $1 \%$ and 2\% respectively stated they purchased these products every day; however in South Africa this was 5\%. In Ireland 6\% stated they purchased weekly, in South Africa $13 \%$ and in England 16\%. Medicines purchased most frequently in Ireland included Nurofen Plus ${ }^{\circledR}$, Solpadeine ${ }^{\circledR}$ and Feminex ${ }^{\circledR}$. Medicines purchased most frequently in South Africa included Adcodol ${ }^{\circledR}$ and Benylin ${ }^{\circledR}$. Medicines purchased regularly in England included Cocodamol ${ }^{\circledR}$, Nurofen ${ }^{\circledR}$ and Solpadeine ${ }^{\circledR}$.

Knowledge of codeine containing products

Respondents were asked to state their main sources of information in relation to medicine containing codeine. In all three countries, the most frequent answer was from the physician or pharmacist (Fig. 3). However, this was followed by advice from family and friends in both Ireland (23\%) and South Africa (26\%). In England, 27\% stated they sourced their information from the packaging or leaflet. 


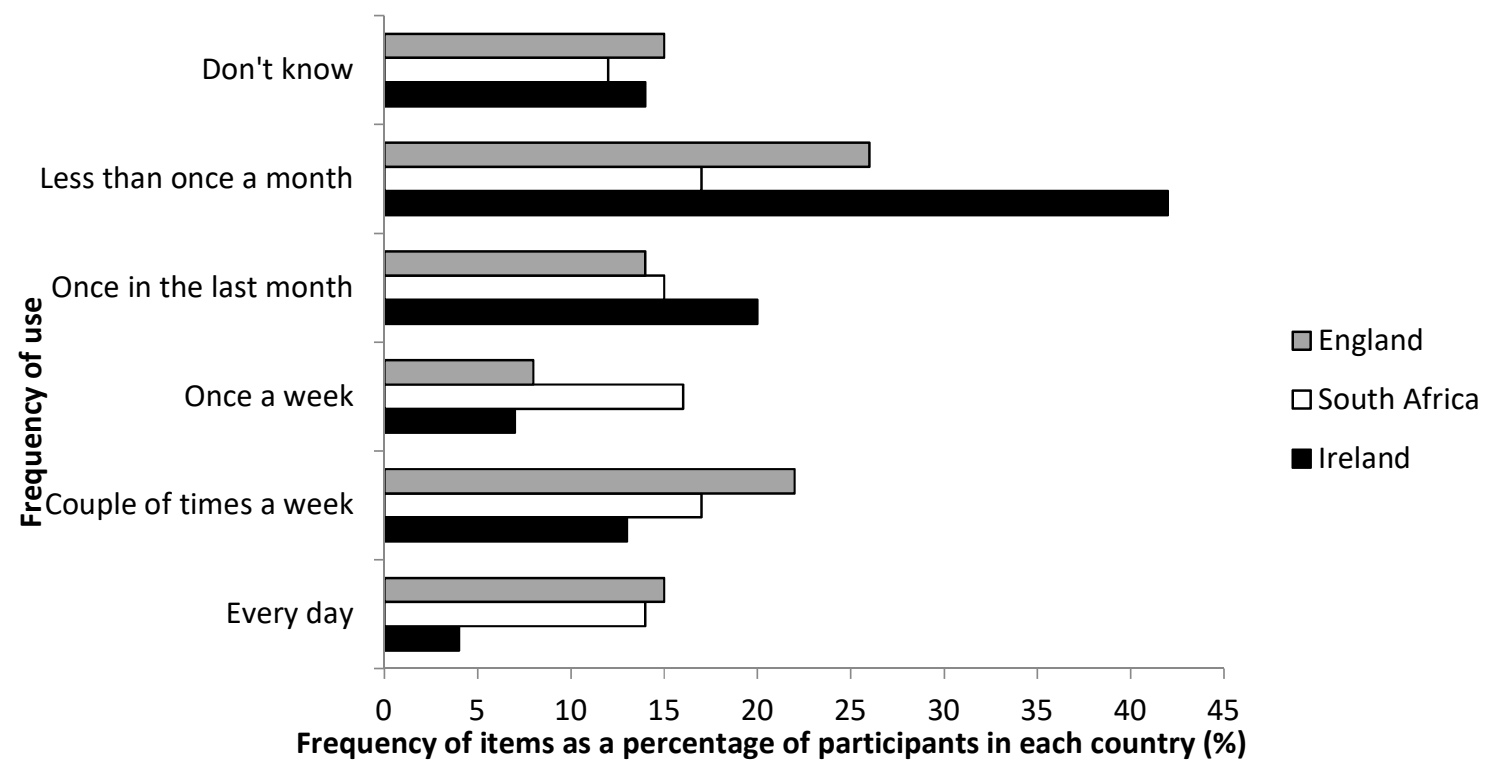

Figure 2. Frequency of use in the last year

To a statement concerning effectiveness, the majority in all three countries agreed that it is effective (Table 4; 79\% v 73\% v $80 \%$ ). Only, $34 \%$ of respondents in Ireland, 43\% in South Africa and 25\% in England disagreed with the statement that codeine containing medicines should be prescription only. In Ireland and England a similar proportion agreed that these medicines were harmful and addictive. However, in South Africa the proportion was lower. A one-way between-groups analysis of variance and a chi-square test were conducted and revealed a statistically significant difference between countries $(p=0.00)$, post hoc analysis indicated that South Africa was significantly different to both Ireland and England for both statements.

An independent-samples T-Test was used to compare gender against areas of knowledge. In Ireland, this was statistically significant for prolonged use of such products is harmful $(\mathrm{p}=0.000)$ and medicine containing codeine is addictive $(p=0.000)$. In both of these areas females agreed to a greater extent with the statements compared with males. In England, females appeared to agree more strongly than males that prolonged use of codeine containing products is harmful $(\mathrm{p}=0.026)$ and that such products are addictive $(\mathrm{p}=0.022)$. However, when a Chi-square test for independence was run using the categorical data from England, no significant association was identified.
Impact of age was explored on knowledge of codeine containing products. In England, there was a statistically significant difference in relation to the statements that prolonged use of codeine containing products is harmful $(\mathrm{p}=0.001)$ and that medicine containing codeine is addictive ( $\mathrm{p}=0.000)$. The $41-50$ $(p<0.00)$ and $61-70(p<0.05)$ age groups agreed more strongly with the first statement compared to the 2130 age group. Similarly, the $41-50(p<0.00)$ and 51$60(p<0.01)$ age groups agreed with the second statement more than the 21-30 age group.

Level of education was compared against areas of knowledge of medicinal products containing codeine. In Ireland, this was statistically significant for prolonged use of codeine containing products is harmful $(\mathrm{p}=0.01)$ and medicine containing codeine is addictive $(\mathrm{p}=0.04)$. Those with college or a technical background agreed to a greater extent with the statements compared with those who completed secondary school $(\mathrm{p}<0.01$ and $\mathrm{p}<0.05)$. In South Africa, those educated to college level appeared to agree more strongly, compared to those who had completed secondary level education, that medicine containing codeine should be available on prescription only $(\mathrm{p}=0.02)$; that prolonged use of codeine containing products is harmful $(\mathrm{p}=0.01)$ and that medicine containing codeine is addictive $(\mathrm{p}=0.05)$. 
Table 3. Purchase of medicine containing codeine containing products

\begin{tabular}{|c|c|c|c|c|c|c|}
\hline & \multicolumn{2}{|c|}{$\begin{array}{l}\text { Ireland }^{\mathrm{a}} \\
(\mathrm{N}=\mathbf{3 2 8})\end{array}$} & \multicolumn{2}{|c|}{$\begin{array}{l}\text { South Africa }^{\mathrm{a}} \\
(\mathrm{N}=665)\end{array}$} & \multicolumn{2}{|c|}{ England $(\mathbf{N}=237)^{a}$} \\
\hline & n & $\%$ & $\mathbf{n}$ & $\%$ & $\mathbf{n}$ & $\%$ \\
\hline \multicolumn{7}{|c|}{ Purchased in the last year } \\
\hline Yes & 202 & 63 & 471 & 74 & 115 & 48 \\
\hline No & 84 & 26 & 163 & 26 & 101 & 43 \\
\hline Don't know & 34 & 11 & 0 & 0 & 21 & 9 \\
\hline \multicolumn{7}{|c|}{ Where do you purchase } \\
\hline Local pharmacy & 212 & 65 & 487 & 73 & 107 & 45 \\
\hline Supermarket & 16 & 5 & --- & --- & 29 & 12 \\
\hline The internet & 1 & 0.3 & 3 & 0.5 & 0 & 0 \\
\hline Other & 0 & 0 & 9 & 1 & 0 & 0 \\
\hline \multicolumn{7}{|c|}{ Frequency of purchase } \\
\hline Every day & 2 & 1 & 27 & 5 & 2 & 2 \\
\hline Weekly & 13 & 6 & 65 & 13 & 20 & 16 \\
\hline Monthly & 52 & 23 & 158 & 32 & 27 & 22 \\
\hline Very occasionally & 136 & 63 & 206 & 41 & 68 & 56 \\
\hline Never buy it & 6 & 3 & 6 & 1 & 3 & 3 \\
\hline Don't know & 8 & 4 & 37 & 8 & 2 & 1 \\
\hline
\end{tabular}

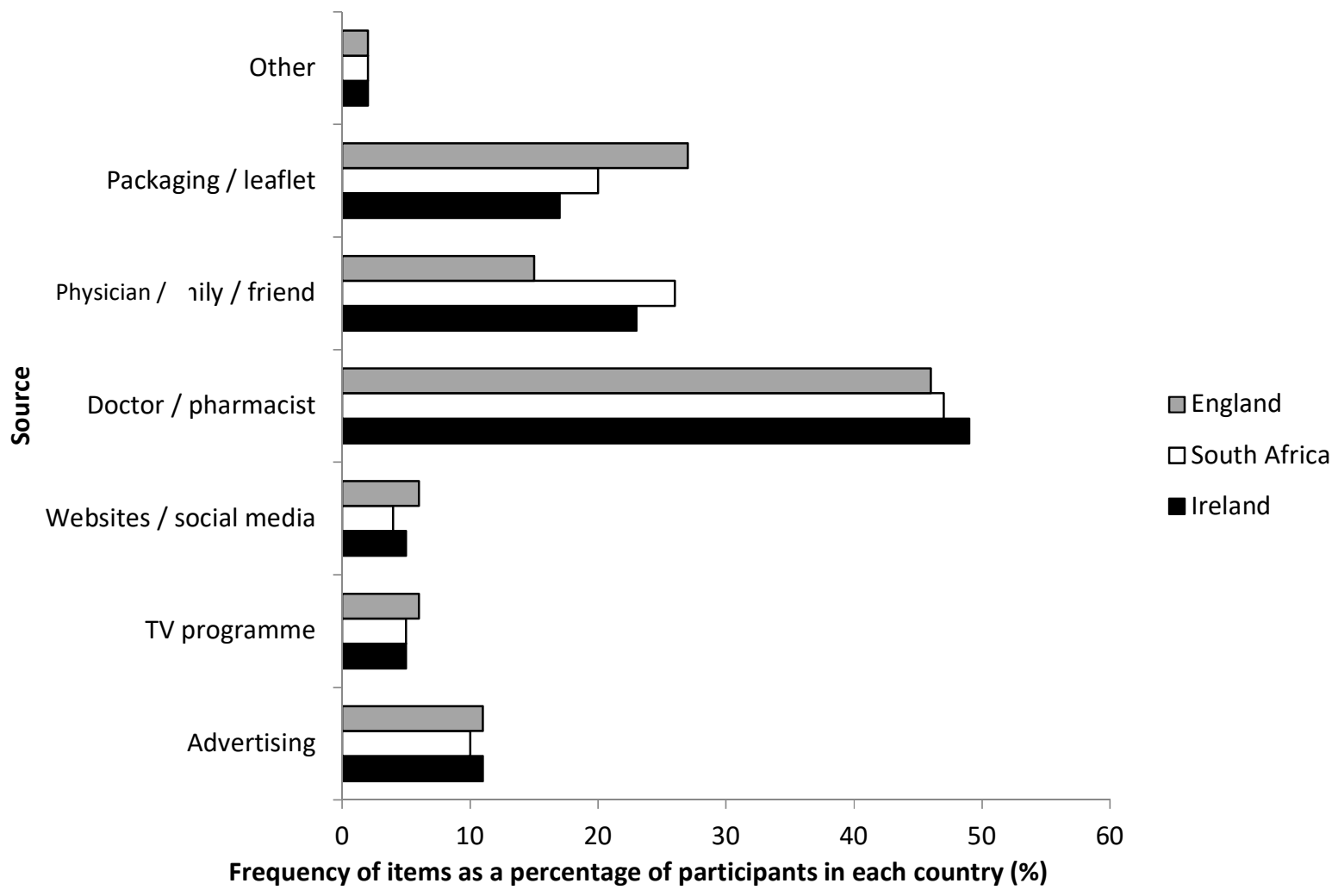

Figure 3. Sources of Information 
Table 4. Knowledge relating to codeine containing products

\begin{tabular}{|c|c|c|c|}
\hline Statements & $\begin{array}{l}\begin{array}{l}\text { Ireland }^{\mathrm{a}} \\
(\mathbf{N}=\mathbf{3 2 8})\end{array} \\
\text { Mean }( \pm \mathrm{SD}) \\
\mathbf{n}(\%)\end{array}$ & $\begin{array}{l}\begin{array}{l}\text { South Africa } \\
(\mathbf{N}=665)\end{array} \\
\text { Mean }( \pm \mathrm{SD}) \\
\mathbf{n}(\%)\end{array}$ & $\begin{array}{l}\begin{array}{r}\text { England }^{\mathrm{a}} \\
(\mathbf{N}=\mathbf{2 3 7})\end{array} \\
\text { Mean }( \pm \mathrm{SD}) \\
\mathbf{n}(\%)\end{array}$ \\
\hline Medicine containing codeine is effective & $\begin{array}{l}1.12(0.84) \\
251(79)\end{array}$ & $\begin{array}{l}0.97(0.97) \\
\mathbf{4 3 7}(\mathbf{7 3 )}\end{array}$ & $\begin{array}{l}0.96(0.71) \\
\mathbf{1 7 7}(\mathbf{8 0})\end{array}$ \\
\hline $\begin{array}{l}\text { Medicine containing codeine is safe to } \\
\text { use }\end{array}$ & $\begin{array}{l}0.53(0.90) \\
\mathbf{1 7 7}(\mathbf{5 8})\end{array}$ & $\begin{array}{l}0.52(1.0) \\
\mathbf{3 1 0}(\mathbf{5 2})\end{array}$ & $\begin{array}{l}0.51(0.90) \\
114(54)\end{array}$ \\
\hline $\begin{array}{l}\text { Medicine containing codeine should be } \\
\text { available on prescription only }\end{array}$ & $\begin{array}{l}0.02(1.16) \\
99(32)\end{array}$ & $\begin{array}{l}-0.21(1.30) \\
\mathbf{1 8 0}(\mathbf{3 0})\end{array}$ & $\begin{array}{l}0.21(1.11) \\
84(39)\end{array}$ \\
\hline $\begin{array}{l}\text { Prolonged use of medicine containing } \\
\text { codeine is harmful }\end{array}$ & $\begin{array}{l}0.98(0.96) \\
\mathbf{2 1 0}(\mathbf{6 7})\end{array}$ & $\begin{array}{l}0.57(1.11) \\
271(45)^{* * *}\end{array}$ & $\begin{array}{l}0.82(0.92) \\
133(62)\end{array}$ \\
\hline Medicine containing codeine is addictive & $\begin{array}{l}0.91(0.97) \\
195(63)\end{array}$ & $\begin{array}{l}0.39(1.05) \\
\mathbf{3 1 5}(\mathbf{5 2})^{* * *}\end{array}$ & $\begin{array}{l}0.80(0.96) \\
127(60)\end{array}$ \\
\hline
\end{tabular}

\section{DISCUSSION}

The literature indicates that patients develop an iatrogenic codeine dependence as a result of initially taking this medication to manage pain; the literature also indicates that others commence using it to manage stress, anxiety or help them sleep (1-2). Thus, minorities in this survey in each country admitted to use of codeine containing products for relaxant effects.

The management of family centred stresses tends to fall upon women (30) and non-prescription codeine containing products provide an accessible destress intervention. This can be seen in the two most popular products consumed by South Africans which were Adco Dol ${ }^{\circledR}$, a product used to manage 'general body pain' with an associated sedative effect and Benylin ${ }^{\circledR}$ which has a sedative effect. Less support in South Africa for prescription only may reflect the fact that more daily use of these products when combined with having to obtain prescription from a physician (31), was perceived as adding an unacceptable expense to a product perceived as relatively benign.

Availability and easy access to codeine containing medicine greatly reinforces perceptions of harmlessness and willingness to seek out and use the product regularly (4-6). The majority of respondents said they purchased these products in local pharmacies. However, it should be noted that as the survey was conducted in community pharmacy outlets this sample may be likely to state that they purchased these products in the pharmacy and not elsewhere (e.g. online).

In terms of level of regular use, the results of the survey were ambiguous; particularly for South Africa and England where differences between those who took such products regularly on a weekly basis and those who used the product less than once a month were evenly split. Whilst those using it weekly were worryingly high, it is perhaps the higher comparative figure for England that is a surprise (bearing in mind the socio-economic position of the South Africa population is considerably less favourable than in England). These results suggest that comparative cultural aspects of OTC use need to be further examined. This is further reinforced considering the substantial difference between England, South Africa and Ireland in using combination analgesics, with $94 \%$ of English respondents using these analgesics compared to $64 \%$ and $55 \%$ in Ireland and South Africa respectively.

In all three countries the most commonly bought products are amongst those with a high brand recognition. These results would appear to give some credence to the limited evidence that branding plays an important role in consumer choice of medicine (22-25). However, what is striking is that research on the relationship between advertising and use of OTC products such as Solpadeine is limited. It needs to be further examined within the context of people developing dependency.

Insert leaflets are often not consulted by consumers and advertising's role is considerable in 
terms of information reception (19-21). Whilst the overall results would not necessarily run counter to this finding (see Table 2), the survey did indicate that this is more nuanced than the literature suggests. Thus, for example, women in all three countries were more likely to read the insert leaflet than men (though not statistically significant).

There were differences between countries in terms of sources of information, with more people in England stating they got information from the leaflet; whereas more people in South Africa and Ireland said they got information from family and friends (perhaps reflecting a cultural difference in the strength and proximity of family relationships). The majority in all three countries indicated that they relied on medical professionals and pharmacists for advice and information.

The literature indicates that highly educated people are more aware of OTC medicine risks than those less educated (4). The survey results appear to support this conclusion for Ireland and South Africa. However, people in England seem more aware of warnings about dangers of codeine containing products and that was a statistically significant difference. One possible reason for this, other than differences in package design in different jurisdictions (which would not account for the difference with Ireland), might be the way products are displayed or again cultural factors as to how different societies are socialised to recognise and internalise signs of risk/ warnings.

Just over half of all those surveyed in the three countries viewed codeine containing products as a safe medication. In Ireland, women were more likely to view such products as harmful though this was not statistically significant in England and South Africa. In England there was an age difference, with older people (those over 40) more likely to perceive codeine containing products as harmful. This was not the case, however, in Ireland and South Africa. These results would appear broadly reflective of the literature which indicates that people in general do not perceive codeine containing products as harmful, even though they are aware of their potential dangers $(4,13-14,32)$.

Finally, with regards to our samples' views on whether or not to make codeine containing products a prescription only medicine there was a considerable number of people in Ireland and England who were not against this proposition and even in South Africa there was majority support. Again, within this context a number of features should be noted, including that in Ireland and South Africa, the higher respondents' education the more likely they were to support this proposition (it should be noted that people in England had the highest level of agreement that codeine containing products should be a prescription only drug, with level of education not being a significant factor). The level of disagreement with the proposition in South Africa (43\%) can be seen as aligned with the fact that South Africans were the least likely of the three samples to view such products as harmful. Overall, the challenge lies in ensuring availability of codeine containing medicines for therapeutic use whilst preventing dependence and related harms. Best practices and innovations have been identified which focus on the products retail lifecycle from manufacture to community pharmacy practitioner (33). These innovations warrant further consideration and inclusion in regulatory and policy debate in each country in order to reduce misuse, dependence and related health harms.

\section{Limitations of the study}

This study has several limitations and hence interpretations should be treated with some caution. A disadvantage of implementing questionnaires, which being anonymous and self-reporting reduce bias and facilitates honest responses, is that it is difficult to establish cause-and-effect conclusions. Therefore, demographics outlined in the study may not be the proximal reason for some of the chosen answers and the results remain descriptive in nature. With regards analysis, the decision was taken to use parametric tests at times, as these tests furnish additional information in relation to the data. In order to support this further, chi-square analysis was also conducted using the same variables and where only the parametric tests were significant, this was highlighted. The inability statistically to generalise findings due to the sampling method selected is recognised as a limitation, although as the study was exploratory in nature, it was deemed as the most appropriate choice. However, the sample size in each of the three sites was of a relatively large size and therefore the data being gathered possess a better description of the relative characteristics of the general population involved in the study.

\section{CONCLUSION}

This study aimed to explore comparatively customer use, sources of information and knowledge of OTC codeine containing medicinal products in three countries. In this context, the survey indicates two important factors which should be examined in further research. The first relates to cultural differences in perceptions, knowledge seeking and communicating with regard harms and harm reduction. It is an issue that one might argue is pressing, from a public health perspective. The 
second area is the issue of gender differences. This survey would indicate that women are more likely to engage with insert patient leaflets on codeine containing products and its potential harms. Bearing in mind the significance of women within a family context this is an area worth examining in terms of how to disseminate information to reduce harms more effectively then the literature indicates is presently the case.

\section{FUNDING ACKNOWLEDGEMENTS}

We acknowledge the funding received by the Codemisused Project from the European Community's Seventh Framework Programme FP7/2007-2013 under the grant agreement number 611736.

\section{REFERENCES}

1. Frei MY, Nielsen S, Dobbin MD, Tobin CL. Serious morbidity associated with misuse of over-the-counter codeine-ibuprofen analgesics: a series of 27 cases. Med J Aust. 2010; 193: 294-296.

2. Van Hout MC, Bergin M, Foley M, Rich E, Rapca AL, Harris R, Norman I. A Scoping Review of Codeine Use, Misuse and Dependence: Final Report. CODEMISUSED Project European Commission, 7th Framework Programme, EU. Brussels. Available at www.codemisused.org; 2014 Accessed 16.06.2018.

3. Kohli E, Buller A. Factors Influencing Consumer Purchasing Patterns of Generic versus Brand Name Over-the-Counter Drugs. Southern Med J. 2013; 106: 155-160.

4. Matoulková P,Dosedel M, Ruzkova B, Kubena A. Information and awareness concerning ibuprofen as an ingredient in over the counter analgesics: a questionnaire-based survey of residents of retirement communities. Acta Poloniae Pharmaceutica. 2013; 70: 333-338

5. Casati A, Sedefov R, Pfeiffer-Gerschel T. Misuse of Medicines in the European Union: A Systematic Review of the Literature. Eur Addict Res. 2012; 18: 228-245.

6. Francis SA, Barnett N, Denham M. Switching of prescription drugs to over-the-counter status: is it a good thing for the elderly? Drugs Aging. 2005; 22: 361-70.

7. Nielsen S, Van Hout MC. Over-the-Counter Codeine-from Therapeutic Use to Dependence and the Grey Areas in Between. In: Ellenbroek B, Geyer M, Marsden C, eds. The Misuse of Licit and Illicit Drugs in Psychopharmacology. Current Topics in Behavioral Neuroscience. Berlin: Springer Link; 2015.

8. Sproule BA, Busto UE, Somer G, Romach MK, Sellers EM. Characteristics of dependent and nondependent regular users of codeine. J Clin Psychopharm. 1999; 19:367-372.
9. Cooper, RJ. Over-the-counter medicine abuse: a review of the literature. J Subst Use 2013; 18:82-107.

10. Dobbin, M, Tobin, C. Over-the-counter Ibuprofen/Codeine Analgesics: Misuse and Harm. Melbourne, Australia: Drugs Policy and Services Branch and Department of Human Services, Victoria. 2008

11. Bower A, Landreth Grau S, Taylor VA. Over-thecounter vs. prescription medications: are consumer perceptions of the consequences of drug instruction non-compliance different? Int J Consumer Stud. 2012; 6431.2011.01093.x

12. Wilcox CM, Cryer B, Triadafilopoulos G. Patterns of use and public perception of over-the-counter pain relievers: focus on non-steroidal anti-inflammatory drugs. J Rheum. 2005; 32:2218-24.

13. Wirtz VJ, Taxis K, Dreser A. Pharmacy customers' knowledge of side effects of purchased medicines in Mexico. Trop Med \& Int Health. 2009; 14:93-100.

14. Krska J, Kennedy E. Expectations and experience of customers purchasing OTC medicines in pharmacies of the North of Scotland. Pharma J. 2011; 256: 354356.

15. Justin Temu, Mwambete DK, Nyaki D. Public knowledge, attitude and perception of over the counter medicines: case study in Dar es Salaam region, Tanzania. E African J Pub Health. 2010; 7: 282-284.

16. Stosic R, Dunagan F, Palmer H, Fowler T, Adams I. Responsible self-medication: perceived risks and benefits of over-the-counter analgesic use. Int J Pharm Prac. 2011; 19:236-245.

17. Lipsky MS, Taylor CA. The opinions and experiences of family physicians regarding direct-to-consumer advertising. J Fam Prac. 1997; 45:495-499.

18. Liu Y, Doucette WR. Does direct-to-consumer advertising affect patients' choice of pain medications? Current Pain and Headache Reports. 2008; 12:89-93.

19. Ventola CL. Direct-to-Consumer Pharmaceutical Advertising: Therapeutic or Toxic? Pharm Therapeutics. 2011; 36:669-674.

20. Himmel $\mathrm{M}$ et al. What do primary care patients think about generic drugs? Int J Clin Pharma \& Thera. 2005; 43:472-479.

21. Burak LJ, Damico A. College students' use of widely advertised medications. J Amer College Health. 2000; 49:118-121.

22. Dieringer NJ, Kukkamma L, Somes GW, Shorr RI. Self-reported responsiveness to direct-to-consumer drug advertising and medication use: results of a national survey. BMC Health Serv Res. 2011; https://doi.org/10.1186/1472-6963-11-232.

23. Sa'di Al-Haddad M. General public perceptions towards medicines in the state of Penang Malaysia. Arch Pharm Prac. 2012;3:242-253.

24. Lee M, Whitehill KK, Reid LN. Factors Influencing Consumers' Attitudinal and Behavioral Responses to Direct-To-Consumer and Over-the-Counter Drug Advertising. J Heal Comm. 2015;20:431-444. 
25. Arif S, Atta A, Sidra T, Farrukh RA, Adeel A, Aysha A, Syed IA, Shazia A, Sarah H, Syed AR. Consumer's perception regarding pharmaceutical product packaging: A survey of Pakistan. Int J Pharm \& Ana Res. 2014; 3:118-125.

26. Carney $\mathrm{T}$ et al. A Comparative Exploration of Community Pharmacists' Views on the Nature and Management of Over-the-Counter (OTC) and Prescription Codeine Misuse in Three Regulatory Regimes: Ireland, South Africa and the United Kingdom. I J Ment Health \& Addict 2016; 14(4): 351369.

27. Char B, Kwong K. Direct-to-consumer advertising: Australian pharmacists' experiences with nonprescription medicines. Int J Pharm Prac 2010; 18: 4350.

28. Major C, Vincze z. Consumer habits and interests regarding non-prescription medications in Hungary. Fam Prac 2010; 27: 333-338.
29. Villako P, Volmer D, Raal A. Factors influencing purchase of and counselling about prescription and OTC medicines at community pharmacies in Tallinn, Estonia. Acta Poloniae Pharma 2012; 69(2): 335-340.

30. Grzywacz JG, Almeida DM, McDonald DA. WorkFamily Spillover and Daily Reports of Work and Family Stress in the Adult Labor Force. Fam Rel. 2014; 51; 28-36.

31. Harris B, Goudge J, Ataquba JE, McIntyre D, Nxumalo N, Jikwana S, Chersich M. Inequities in access to health care in South Africa. J Pub Heal Pol. 2011; 32:102-123.

32. Van Hout M, Horan A, Santal K, Rich E, Bergin M. Codeine is my companion': misuse and dependence on codeine containing medicines in Ireland. Irish $\mathbf{J}$ Psych Med 2017; 27:341-350.

33. Norman I, Bergin M, Parry CD, Van Hout M. Best practices and innovations for managing codeine misuse and dependence. J Pharm Pharm Sci. 2016; 19: 367-381. 